\title{
Investigation of Main Radiation Source above Shield Plug of Unit 3 at Fukushima Daiichi Nuclear Power Station
}

\author{
Hideo Hiratama $^{1,2^{*}}$, Kenjiro Kondo ${ }^{1,2}$, Seishiro Suzuki ${ }^{1}$, Yoshihiko Tanimura ${ }^{1}$, Kohei Iwanaga ${ }^{1}$, Hiroshi Nagata \\ ${ }^{1}$ Nuclear Regulation Authority, 1-9-9, Roppongi, Minato-ku, Tokyo, Japan 106-8450 \\ ${ }^{2}$ High Energy Accelerator Research Organization, 1-1, Oho, Tsukuba-shi, Ibaraki, Japan 305-0801 \\ *Corresponding Author: hideo.hirayama@kek.jp
}

\begin{abstract}
Pulse height distributions were measured using a CdZnTe detector inside a lead collimator to investigate main source producing high dose rates above the shield plugs of Unit 3 at Fukushima Daiichi Nuclear Power Station. It was confirmed that low energy photons are dominant. Concentrations of Cs-137 under $60 \mathrm{~cm}$ concrete of the shield plug were estimated to be between $8.1 \mathrm{E}+9$ and $5.7 \mathrm{E}+10 \mathrm{~Bq} / \mathrm{cm}^{2}$ from the measured peak count rate of $0.662 \mathrm{MeV}$ photons. If $\mathrm{Cs}-137$ was distributed on the surfaces of the gaps with radius $6 \mathrm{~m}$ and with the averaged concentration of 5 points, $2.6 \mathrm{E}+10 \mathrm{~Bq} / \mathrm{cm}^{2}$, total amount of Cs-137 is estimated to be $30 \mathrm{PBq}$.
\end{abstract}

KEYWORDS: Unit 3, Fukushima Daiichi, CdZnTe, pulse height distribution, EGS5

\section{Introduction}

Ambient dose equivalent rates at the operation floor of Fukushima Daiichi Nuclear Power Station Unit 3 were very high. It was order of $\mathrm{Sv} / \mathrm{h}$ at maximum at $5 \mathrm{~m}$ from the floor surface. Maximum dose rate was reduced to about 200 $\mathrm{mSv} / \mathrm{h}$ by removing debris, cutting and sucking of concrete surface using remote devices. It was estimated that about 5 $\mathrm{mm}$ of concrete surface was removed by cutting and sucking. The reduction rate of about $20 \%$ is smaller from the fact that contamination by Cs-134 and Cs-137 attached at concrete superficially. We supposed considering the construction of shield plugs shown in Figure 1 that Cs-134 and Cs-137 attached between gaps of 3 layers of shield plugs at which gases including high density Cs-134 and Cs-137 leaked through at the time of accident. If this estimation is correct, the main component of the photon field above the shield plug is scattered photons within $60 \mathrm{~cm}$ concrete. To confirm this estimation, measurements of pulse height distribution were performed using a CdZnTe detector inside a lead collimator with enough shielding.

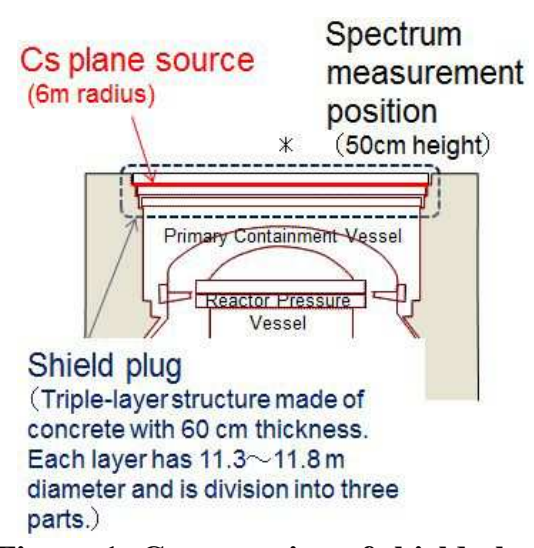

Figure 1: Construction of shield plug.

\section{Detector and collimator}

The collimator shown in Figure 2 was used to measure pulse height distribution of photons emitted from small region outside the shield plug etc. The collimator consists with a $30 \mathrm{~cm}$ x $30 \mathrm{~cm}$ x $30 \mathrm{~cm}$ lead block. This lead block was set inside a $2 \mathrm{~cm}$ thick iron container. A $0.8 \mathrm{~cm}$ diameter hole is opening at a center of the lead block and a $1 \mathrm{~cm} \mathrm{x} 1$ $\mathrm{cm}$ x $1 \mathrm{~cm} \mathrm{CdZnTe} \mathrm{detector} \mathrm{(GR-1,} \mathrm{Kromek}{ }^{1)}$ ) was set at $12.5 \mathrm{~cm}$ from bottom of the lead block.

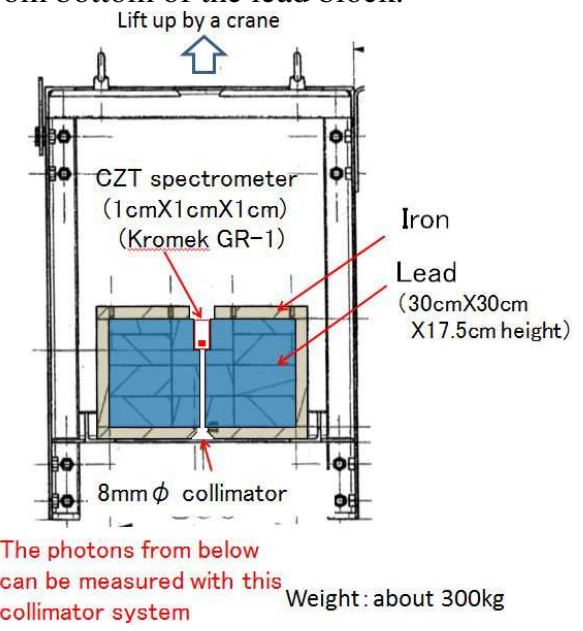

Figure 2: Schematic drawing of the collimator system

If 1 photon $/ \mathrm{cm}^{2}$ toward the detector uniformly enters the bottom of the collimator, numbers of unscattered photons become as follows ;

$\begin{array}{rll}0.662 \mathrm{MeV}: & \text { through hole } & 0.503 \\ \text { through lead } & 0.000515 \\ 0.3 \mathrm{MeV} \quad: \text { through hole } & 0.503 \\ & \text { through lead } & 1.26 \mathrm{E}-20 .\end{array}$


From this result, it is clear that contributions from photons transmitting lead can be neglected.

Weight of the collimator system is about $300 \mathrm{~kg}$. This system was set at the position that the detector surface was $50 \mathrm{~cm}$ from the surface of the floor by using a huge remote operating crane.

\section{Measurement points and results}

24 points were selected for pulse height distribution measurements from various environments; the shield plug of the reactor, iron shield on the floor, the spent fuel pool etc. The measurement points are densely-arranged above the shield plugs and their joints because high level contamination is expected.

Measurement points and measured pulse height distributions are shown in Figure 3 and 4, respectively. As the full energy absorption peaks, corresponding to gamma-rays from Cs-134 and Cs-137 only are detected. All pulse height distributions show high count rates at low energy region mainly corresponding to scattered photons.

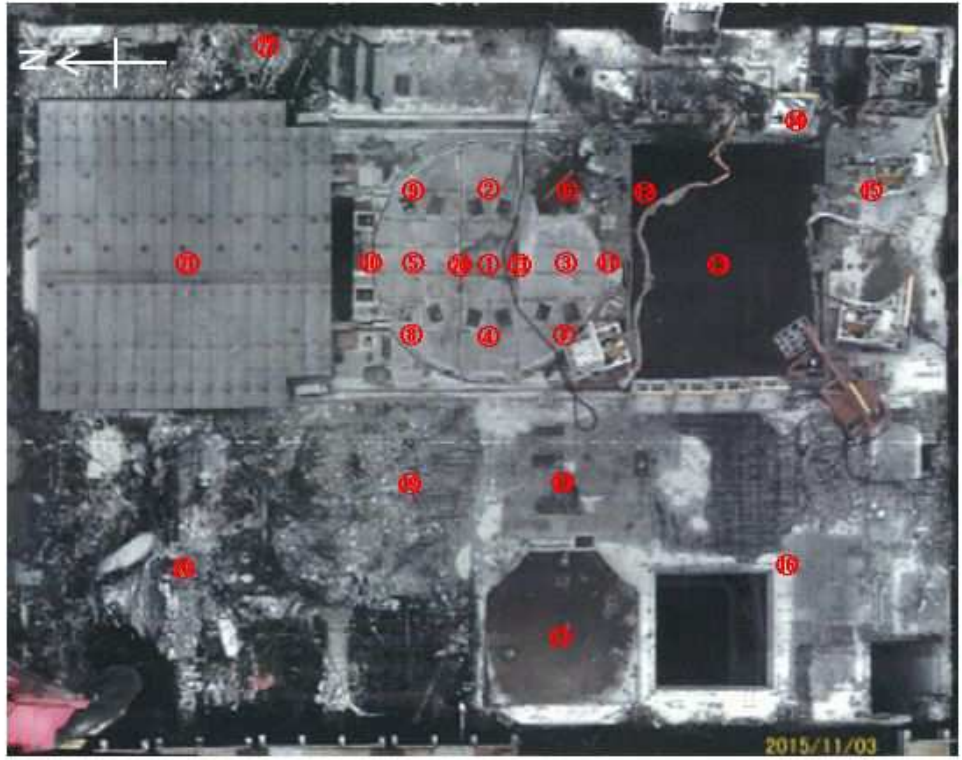

Figure 3: Measurement points

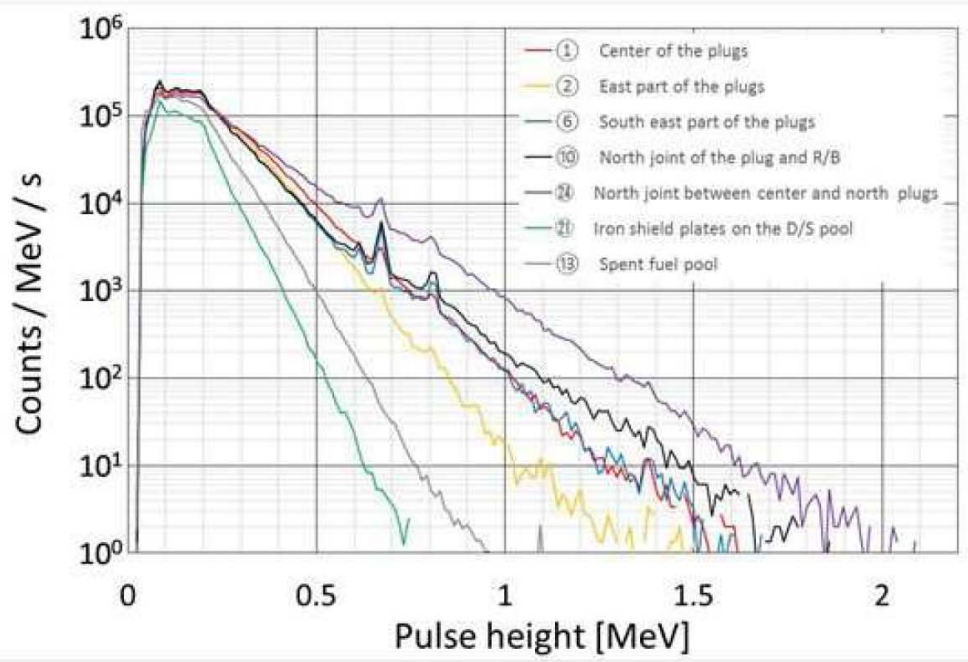

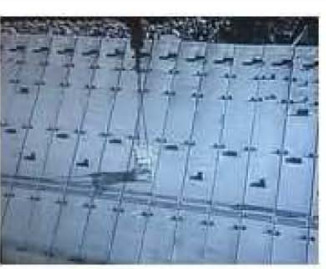

(2)Iron shield ${ }^{*}$ plates on the DS pool $\quad * 15 \mathrm{~cm}$ thick

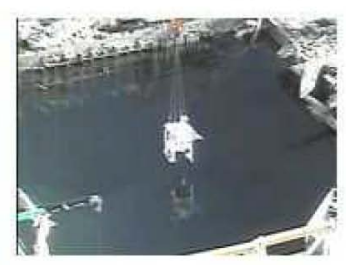

(1) Spent fuel pool

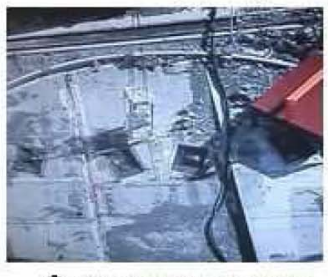

(2) East part of the plugs

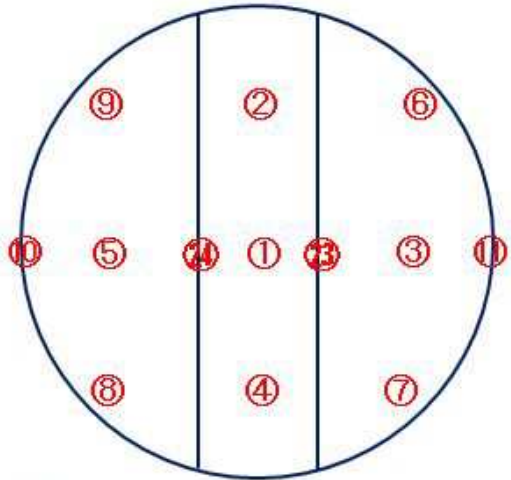

Expanded figure of shield plugs of the reactor
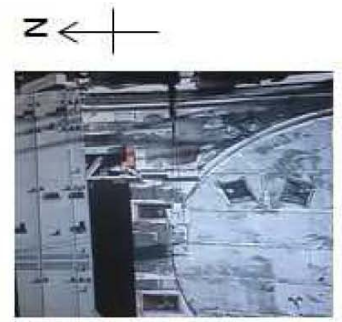

(10) North joint of the plug and $\mathrm{R} / \mathrm{B}$

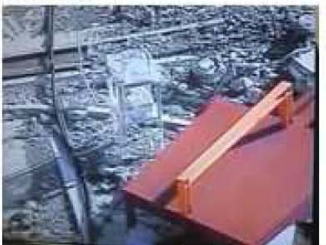

(6) South east part of the plugs (Rubble remain on the floor)

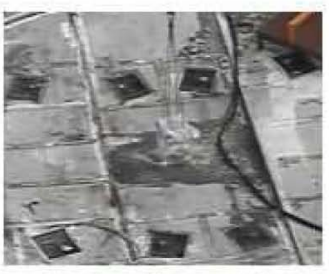

(1) Center of the plugs

Figure 4 :Measured pulse height distributions 


\section{Estimation of concentration of Cs-137 at the gap of the shield plug \\ 1. Conversion factor from peak count rates to a concentration density}

Numbers of unscattered photons from radial segmented plane sources of Cs-137 entering to the CdZnTe detector inside the collimator system were calculated with EGS5 Monte Carlo code ${ }^{2)}$. The calculated $0.662 \mathrm{MeV}$ photons entering on the detector surface became 7.5E-09 photons $/ \mathrm{sec}$ per $\mathrm{Bq} / \mathrm{cm}^{2}$. The contribution of Cs-137 outside $7.2 \mathrm{~cm}$ from a center of the collimator was about $1 \%$. From this result, an effective source radius for this measurement can be treated as $7 \mathrm{~cm}$.

A peak efficiency of the detector for $0.662 \mathrm{MeV}$ photon was 0.078 by calculating with EGS5 supposing that photons entered normally on the detector surface and uniformly within the collimator radius.

The conversion coefficient from peak count rates of $0.662 \mathrm{keV}$ photons to a concentration density became $1.7 \mathrm{E}+09 \mathrm{~Bq} / \mathrm{cm}^{2}$ per cps.

\section{Estimation of concentration}

Concentrations were estimated from the measured peak counts rates and the obtained conversion coefficient at the point from No.1 to No.5 which were above the shield plugs except their joints. Results are shown in Table 1. Concentrations varied almost factor 5 between these points from $8.0 \mathrm{E}+09$ to $5.7 \mathrm{E}+10 \mathrm{~Bq} / \mathrm{cm}^{2}$. If $\mathrm{Cs}-137$ was distributed on the surfaces of the gaps of three shield plugs with radius $6 \mathrm{~m}$ and with the averaged concentration of these 5 points, $2.6 \mathrm{E}+10 \mathrm{~Bq} / \mathrm{cm}^{2}$, total amount of $\mathrm{Cs}-137$ is estimated to be $30 \mathrm{PBq}$ and is about $10 \%$ of the estimated total inventory of Cs-137 at Unit $3^{3)}$.

\section{Conclusion}

From our measurement, it can be expected that larger amount of Cs-137 than that emitted to environment at the time of accident exists between the gaps of the shield plugs. This must be considered at future processes of decommissioning of the reactor.

\section{Acknowledgment}

We have to express out appreciation to High Energy Accelerator Research Organization for providing the collimator system. We are also immensely grateful to Fukushiam Daiichi Nuclear Power Station related Tokyo Electric Power Company, Toshiba Corporation and Kajima Corporation JV for their helping at Unit 3 measurement.

Table 1 Estimated Cs-137 concentration

\begin{tabular}{|l|c|c|}
\hline Point & $\begin{array}{c}\text { Peak count } \\
\text { rates }(\mathrm{cps})\end{array}$ & $\begin{array}{c}\text { Concentration } \\
\left(\mathrm{Bq} / \mathrm{cm}^{2}\right)\end{array}$ \\
\hline No. 1 & 32.8 & $5.7 \mathrm{E}+10$ \\
\hline No. 2 & 7.19 & $1.2 \mathrm{E}+10$ \\
\hline No. 3 & 23.4 & $4.0 \mathrm{E}+10$ \\
\hline
\end{tabular}

\begin{tabular}{|l|l|l|} 
No.4 & 4.72 & $8.1 \mathrm{E}+09$ \\
\hline No. 5 & 8.67 & $1.5 \mathrm{E}+10$ \\
\hline
\end{tabular}

\section{References}

1) GR1-Gamma Ray Spectrometer, Kromek Group plc $<$ http://www.kromek.com/index.php/products/all-nuclear-pr oducts/gr1-gamma-ray-spectrometer> (confirmed 27, January, 2016)

2) H. Hirayama, Y. Namito, A. F. Bielajew, S. J. Wilderman and W. R. Nelson, "The EGS5 Code System", SLAC-R-730 (2005) and KEK Report 2005-8 (2005).

3) Kenji Nishihara, Hiroki Iwamoto, and Kenya Suyama, “ Estimation of Fuel Compositions in Fukushima-Daiichi Nuclear Power Plant", JAEA-Data/Code 2012-018(2012). 